\title{
MOVIMENTOS SOCIAIS E POLÍTICAS PÚBLICAS: REPENSANDO ATORES E OPORTUNIDADES POLÍTICAS
}

\author{
Rebecca Neaera Abers
}

é professora Associada da Universidade de Brasília. Brasília, DF, Brasil.

E-mail: rebecca.abers@gmail.com

Orcid: 0000-0002-4816-9345

Marcelo Kunrath Silva

é professor titular do Departamento de Sociologia da Universidade Federal do Rio Grande do Sul.

Porto Alegre, RS, Brasil.E-mail: mksilva@ufrgs.br

Orcid: 0000-0003-2817-0856

Luciana Tatagiba

é professora livre-docente do Departamento de Ciência Política Universidade Estadual de Campinas.Campinas, SP, Brasil.E-mail: tatagiba@g.unicamp.br

Orcid: 0000-0002-5004-3012

http://dx.doi.org/10.1590/0102-015046/105

\section{Introdução}

A relação entre movimentos sociais e políticas públicas tornou-se um dos temas centrais na agenda brasileira de estudos sobre movimentos sociais. Tal centralidade expressa reconfigurações das relações entre os movimentos sociais e o Estado brasileiro ao longo das últimas quatro décadas, as quais tiveram implicações tanto para a organização e atuação dos movimentos como para a formulação e implementação das políticas. Um dos principais desafios deste campo de estudos tem sido construir ferramentas analíticas que nos permitam descrever esses processos e explicar as mudanças ocorridas ao longo do tempo.

O estudo da inserção de movimentos sociais no processo de produção das políticas públicas, vis-à-vis outros atores/ redes dentro e fora do Estado e as condições que favorecem ou limitam sua influência na modelagem das políticas é uma 
agenda em franco desenvolvimento que já tem mostrado importantes frutos. Um dos aspectos mais proeminentes nessa produção é o reconhecimento da mútua constituição, ou seja, de que os movimentos sociais importam para as políticas públicas e que as políticas públicas, por sua vez, impactam a emergência, o desenvolvimento e o sucesso dos movimentos (Lavalle et al., 2018).

Neste artigo buscamos colaborar com o desenvolvimento dessa agenda, refletindo sobre como movimentos sociais se relacionam com as políticas públicas. Para tanto, desenvolvemos e qualificamos argumentos apresentados preliminarmente por Tatagiba, Abers e Silva (2018). Nesse texto, propusemos um modelo de análise para abordar a agência dos movimentos sociais nas políticas públicas a partir de sua atuação na construção, proposição e defesa de modelos alternativos de políticas públicas. Já neste artigo, buscamos oferecer um modelo analítico para abordar aquilo que a literatura tradicionalmente apreende como o "contexto político", que condicionaria a atuação dos movimentos sociais nas políticas públicas.

Nossa proposta parte do reconhecimento de dois problemas na maneira como o "contexto político" foi abordado pela literatura de movimento social no Brasil e no exterior. No que se refere à literatura nacional, apesar dos avanços da última década, não temos ainda uma reflexão sistemática sobre como abordar o "contexto político" e, particularmente, como ele importa para a análise de formas e resultados da atuação dos movimentos sociais nas políticas públicas. No que se refere à literatura internacional, observa-se que, embora vários autores problematizem o conceito de "estrutura de oportunidade política”, o contexto ainda emerge em grande parte das análises como um cenário inerentemente externo aos movimentos que estabelece oportunidades ou ameaças e constrange suas ações. Neste texto propomos dialogar criticamente com essas literaturas a partir de dois 
objetivos complementares: de um lado, propor um modelo teórico que possibilite analisar de forma sistemática e qualificada o "contexto político" no qual se constituem e atuam os movimentos sociais; de outro lado, retirar o "contexto político" da condição de cenário, rejeitando a exterioridade como ponto de partida da análise. Assim, argumenta-se que, ao invés de se relacionarem com um "contexto político" objetivado e externo que condiciona sua formação e ação, os movimentos sociais estão inseridos em relações de interdependência com os diversos atores e instituições com quem interagem rotineiramente, constituindo o que denominamos de estruturas relacionais. Reconhecemos que a literatura já oferece vários conceitos para abordar tais estruturas relacionais: redes, campos, configurações. No entanto, optamos pelo conceito de "estrutura relacional" para enfatizar que o contexto é constituído por relações entre atores que, uma vez instituídas, estruturam ações futuras.

$\mathrm{Na}$ análise das relações entre movimentos sociais e políticas públicas, as estruturas relacionais que destacamos como sendo relevantes analiticamente são os regimes politicos e os subsistemas de política pública. Seguindo Tilly (2006, 2008), entendemos o regime como a configuração das relações entre os atores politicamente relevantes, a qual condiciona o acesso às discussões e decisões governamentais. Por subsistemas estamos nos referindo às configurações de poder específicas a cada setor de política pública, que conferem aos movimentos sociais diferentes condições de acesso a esses setores e influência sobre eles.

Defendemos que, em função de seu posicionamento nas relações de poder nos regimes e subsistemas, os atores políticos (entre os quais os movimentos sociais) adquirem acesso diferenciado aos recursos materiais e simbólicos que circulam nessas estruturas, influenciando e distinguindo sua capacidade de agência e consequentemente de influência sobre a política pública. Ao mesmo tempo, argumentamos 
que os atores situados nessas estruturas também podem usar os recursos de que dispõem para criativamente construir novas relações. A partir de uma leitura do pragmatismo (Joas, 1997) e da sociologia relacional (Emirbayer, 1997), sustentamos que agência humana é inerentemente criativa, situada e relacional, e que atores produzem e reproduzem estruturas relacionais que, ao mesmo tempo, agem sobre eles. Junto com essa concepção da ação humana vem uma noção de "contexto" como composto pela agência de conjuntos de atores que incluem não somente os interlocutores e adversários dos movimentos sociais, mas também os próprios movimentos. Assim, o "ambiente" em que os movimentos atuam não é externo a eles e sim um conjunto de outros atores com os quais eles interagem.

Para desenvolver este argumento, o artigo encontra-se dividido da seguinte forma: na próxima seção, colocamos nossa proposta em diálogo com a produção brasileira acerca das relações entre movimentos sociais e políticas públicas; na sequência, apresentamos os alicerces teóricos de nossa proposta, as abordagens relacional e pragmatista, explicitando suas contribuições para uma concepção mais agêntica do contexto político; na quarta seção, apresentamos os conceitos de regime e subsistema; por fim, nas considerações finas sintetizamos as principais contribuições do modelo analítico proposto no artigo e a agenda de pesquisa que se abre a partir dele.

\section{0 debate brasileiro}

Os estudos realizados sobre o caso brasileiro têm demonstrado empiricamente que o contexto político importa para a forma como movimentos sociais influenciam (ou não) a política pública e os resultados que alcançam nesse processo. O debate remete à importância das duas dimensões de variação do contexto político que vamos abordar: regimes e subsistemas. 
Na agenda de pesquisa voltada à análise dos processos de institucionalização da participação (conselhos, orçamento participativo, conferências, entre outros), uma área pródiga de estudos a partir dos anos de 1990, a dimensão do regime foi indiretamente trabalhada a partir de dois conceitos: vontade política e projeto político. O primeiro foi pouco desenvolvido teoricamente e tratava do nível de comprometimento dos governantes com a instituição de um sistema participativo que realmente conferisse poder aos participantes (Avritzer e Navarro, 2003; Luchmann, 2002; Silva, 2001) ${ }^{1}$. Já o conceito de projeto político foi produto de um trabalho teórico de maior fôlego, que também buscava descrever e analisar o contexto político mais amplo em que movimentos atuavam. Evelina Dagnino, referência nesse debate, utiliza o conceito de projeto político para se referir à natureza dos conflitos em jogo nos processos de construção da democracia na América Latina (Dagnino, Olvera e Panfichi, 2006, p. 38-39). A intenção era enfatizar o papel da agência humana, partindo do reconhecimento de que, para além das determinações macroestruturais, o terreno da política é também estruturado por crenças e valores. A sobreposição de atores e instituições é central para o conceito, que, por essa via, nega uma abordagem dicotômica e maniqueísta das relações entre os campos da sociedade e do Estado ${ }^{2}$. Contudo, na medida em que o compartilhamento dos conteúdos do projeto político tendia a unificar os atores a ele associados e a opô-los a outro campo de atores também unificados por um projeto político distinto, o conceito se mostrou limitado para a operacionalização da análise empírica das dinâmicas, particularmente dos conflitos internos às coalizões de governo. Embora útil para localizar e nomear os conflitos

\footnotetext{
1 Para uma análise crítica da trajetória do conceito "vontade política" nos estudos da participação, cf. Romão (2010) e Souza (2016).

2 Uma dimensão importante, embora pouco tematizada nesse debate, diz respeito à questão partidária, com destaque para a variável "PT no governo".
} 
em jogo em determinado contexto sociopolítico, o conceito carece de mediações analíticas que permitam apreender como, defrontados com situações dilemáticas, agentes se engajam em escolhas estratégicas e mobilizam ideias e instituições para realizar seus interesses, muitas vezes redefinindo suas alianças e projetos.

Na literatura dos anos 2000, a redefinição da agenda de pesquisa para uma ênfase nos resultados da participação trouxe a política pública para o centro do debate. Isso alimentou uma nova leva de estudos que explorou a heterogeneidade do Estado brasileiro, demonstrando empiricamente que as diferenças setoriais importavam para o acesso ao Estado e a conquista de bens e serviços públicos pelos movimentos.

Os estudos (Cortes, 2009; Gutierres, 2015; Losekann, 2009; Pavez, Toledo e Gonçalves, 2009; Rubim, Fernandes e Rubim, 2010; Serafim, 2013) têm demonstrado que os 20 movimentos produzem mudanças na política pública ao integrarem redes e comunidades de políticas públicas ${ }^{3}$, interagindo com outros atores societais e estatais. Esses estudos evidenciam ainda que o espaço para atuação dos movimentos e os resultados que alcançam no interior dessas redes são condicionados pela trajetória institucional de cada política, em particular a conformação de sua burocracia, e as formas como historicamente se construíram os vínculos entre os atores políticos relevantes. Não raro, as análises apontam a importância de ativistas com filiações múltiplas a partidos, movimentos sociais, órgãos de governo e/ou associações profissionais, não apenas para que as demandas dos

\footnotetext{
3 Redes de política pública "descrevem relações estáveis entre atores que coordenam seus interesses mútuos no quadro de dominios específicos de políticas" (Blanco, Lowndes e Pratchett, 2009, p. 6, grifos nossos). Já comunidade de política pública "refere-se a um número limitado e relativamente estável de membros que dividem os mesmos valores e visão sobre quais devem ser os resultados da política setorial. As decisões são tomadas dentro dessas communities, em processos fechados para outras comunidades e para o público em geral” (Cortes, 2015, p. 132, grifo da autora).
} 
movimentos alcancem o Estado, mas para a própria formulação da demanda como uma política pública. Também mostram que esse esforço dos movimentos para influenciar as políticas não raro tem alterado a configuração dos setores, com a criação de institucionalidades como ministérios, secretarias e Instituições Participativas.

Nesse sentido, por exemplo, Hochstetler e Keck (2007) exploraram a evolução do "ativismo ambiental na sociedade e no Estado” e Losekann (2009) e Oliveira (2016) examinaram a ocupação de cargos por ambientalistas nos governos federais petistas. De acordo com Dowbor (2012), o movimento sanitarista atuou na construção do SUS a partir de postos em órgãos de pesquisa e governamentais. Na área de assistência social, o movimento promoveu uma agenda de direitos, a partir de instituições partidárias e experiências em governos locais (Gutierres, 2015), criando uma policy community (Cortes, 2015) que atuou na construção do Sistema Único de Assistência Social (SUAS). Brandão (2018) examina como técnicos em governos locais e outros profissionais apoiaram a criação do Movimento Nacional de Catadores, e como esses atores defenderam juntos a criação de um novo modelo de resíduos sólidos. Tatagiba e Teixeira (2016) e Blikstad (2017) examinaram como o movimento de moradia participou da construção do modelo autogestionário na habitação em nível local e nacional a partir de estratégias variadas, enquanto Viana (2017) examinou a influência dos defensores desse modelo no interior do governo federal. Serafim (2013) estudou a inserção dos militantes do Fórum da Reforma Urbana nos governos petistas e o impacto sobre a conformação institucional do Ministério das Cidades. Malvezzi (2007), Assis (2009) e Santana e Arsky (2016) mostraram como o programa de construção das cisternas se inseriu na proposição de um modelo alternativo de convivência com o semiárido a partir do fortalecimento dos vínculos entre os atores locais e as agências estatais responsáveis pela 
política. Leitão e Silva (2017) abordaram as relações e disputas entre estratégias confrontacionais e institucionais do movimento negro na construção de políticas e espaços institucionais em prol da igualdade racial. Silva, Rocha e Alves (2012) analisaram as interdependências entre as configurações associativas em dois Territórios da Cidadania, na Bahia e no Rio Grande do Sul, e a implementação da Política de Desenvolvimento Territorial. Conti (2016) e Grisa (2012), por fim, analisaram a atuação de organizações de agricultores familiares na construção e implementação de políticas públicas que desafiaram o modelo do agronegócio.

Para evidenciar as variações setoriais observadas nas pesquisas empíricas e seus impactos sobre os resultados das políticas e os padrões de relação entre movimentos sociais e Estado, tem havido importante esforço de teorização e construção conceitual. Abers, Serafim e Tatagiba (2014) argumentaram que diferentes "repertórios de interação com o 22 Estado" surgem como resultado dos padrões de interação entre Estado e sociedade em diferentes setores de política pública. Em diálogo com a literatura sobre "neodesenvolvimentismo", Pires e Gomide (2016) compararam vários programas governamentais para analisar dimensões "técnico-administrativas" e "política-relacionais" da capacidade estatal, enquanto Souza (2016) examinou as "capacidades conversacionais" de diferentes burocracias federais para construir processos participativos. Teixeira et al. (2016) e Tatagiba e Teixeira (2018) compararam programas governamentais para identificar uma modalidade particular de desenho política pública - os "programas associativos" - voltada a construir e fortalecer redes movimentalistas. Estabelecendo diálogo entre a literatura de intermediação política e a de capacidades estatais, Lavalle et al. (2018) objetivam explicar a institucionalização no Estado de arranjos que criam acesso para movimentos sociais ao processo decisório, o que denominam de "encaixes". 
Em que pesem as contribuições dessa literatura, a relação entre movimentos sociais e contexto político segue subteorizada nos debates sobre casos brasileiros. Identificamos duas limitações principais no tratamento dessa relação. A primeira é a tendência dos estudos em partir de uma compreensão do contexto político como cenário ou ambiente no qual e perante o qual os movimentos sociais reagem. Essa compreensão tende a ter duas decorrências problemáticas para as análises. De um lado, o foco analítico concentra-se exclusivamente na agência dos movimentos sociais, desconsiderando os agenciamentos dos diversos atores e instituições com os quais os movimentos interagem, na medida em que tais agenciamentos são subsumidos ao contexto. De outro lado, ao contrário, o contexto é abordado como uma estrutura que determina externamente oportunidades e constrangimentos para a atuação dos movimentos, destituindo-os de agência. Para responder a esses problemas da literatura que abordou os casos brasileiros nos distanciamos da compreensão do contexto como cenário ou ambiente e desenvolvemos uma abordagem centrada na agência criativa, situada e relacional dos diversos atores (entre os quais os movimentos sociais) que interagem de forma interdependente nos processos de produção de políticas públicas.

A segunda limitação é a ausência de um esforço sistemático para identificar quais dimensões do contexto político importam e como importam para os resultados dos movimentos nas políticas públicas. Para responder a essa lacuna, defendemos que, à medida que buscam influenciar as políticas públicas, os movimentos sociais operam simultaneamente em duas estruturas relacionais mais ou menos distintas na sua configuração: aquela formada pelos atores, interesses e arranjos institucionais estruturados em torno de determinada coalizão governante (regime); e aquela composta pelos atores, interesses e arranjos institucionais que caracterizam determinado setor de política pública (subsistemas). 


\section{Agência e agenciamentos: repensando atores e oportunidades}

Na literatura internacional, a relação entre movimentos sociais e contexto político tem sido predominantemente abordada a partir dos conceitos de oportunidade política e regime. Com esses conceitos, os teóricos do processo político (McAdam, 1982; Tarrow, 1994; Tilly, 1978) buscaram oferecer instrumentos conceituais à análise dos efeitos de estruturas políticas sobre a formação, atuação e resultados dos movimentos. Central na operação analítica da teoria do processo político (TPP) é a configuração da polity, a partir da distinção entre members e challengers (Gamson 1975; Tilly, 1978). A presunção de que movimentos operam por fora das instituições políticas é incluída na própria definição de movimentos sociais desses autores, como se observa em McAdam (1997, p. 173, grifos nossos): "tentativas racionais de grupos excluídos mobilizarem influência suficiente 24 para promover seus interesses coletivos através de meios não-institucionais".

A síntese da contribuição teórica da TPP para análise do contexto político se expressa no conceito de estrutura de oportunidades políticas (EOP), através do qual (sobretudo em sua dimensão "estrutural") se buscava identificar e analisar condições político-institucionais que afetariam de maneira abrangente e generalizada processos de construção, ação e resultados dos movimentos sociais. Uma parte importante dos esforços da literatura se dedicou a identificar os atributos do ambiente político-institucional que conformariam oportunidades ou ameaças à mobilização de movimentos sociais ou às suas chances de sucesso (Tilly, 2006, p. 44).

O conceito de EOP e a perspectiva de análise a ele subjacente têm sido objeto de diversas críticas. Vários autores questionaram as tendências de misturar fenômenos distintos sob o mesmo rótulo; de ignorar o modo como situações de 
adversidade ou repressão podem incentivar protestos, em vez de os desmobilizar; e, com o termo "estrutura", de enfatizar condições gerais que afetariam todos os movimentos de forma similar, entre outros problemas (Amenta e Drew, 2012; Goldstone, 2004; Goodwin e Jasper, 1999; Jasper, 2012). Mesmo autores que tiveram centralidade no desenvolvimento do conceito apresentaram críticas à reificação da EOP como uma estrutura objetiva que independeria da percepção dos atores. Tarrow (1994) rejeita a ideia de que os movimentos simplesmente respondem a oportunidades (e restrições) políticas externas, enfatizando que eles também criam oportunidades para si e para outros atores políticos na medida em que desenvolvem suas ações. McAdam, Tarrow e Tilly (2001, p. 43) propõem um deslocamento do conceito de "estrutura" de oportunidades políticas para o mecanismo de atribuição de oportunidades e ameaças pelos atores. Essa proposta é importante para confrontar lacunas e limites da perspectiva da EOP; no entanto, traz o risco de reduzir oportunidades (e ameaças) políticas às interpretações dos ativistas, ignorando a agência dos outros atores no contexto.

Dialogando com esse debate crítico sobre o conceito de EOP, construímos uma proposta teórica que se baseia em uma forma distinta de abordar a relação dos movimentos sociais com o contexto político em que atuam. Argumentamos que, ao invés de se relacionarem com uma EOP externa, os movimentos sociais estão inseridos em estruturas relacionais constituídas por agenciamentos recíprocos de diversos atores, redes e instituições que nelas agem, incluindo os próprios movimentos.

Ou seja, nossa resposta ao problema identificado na introdução deste artigo - como analisar a relação entre movimentos sociais e contexto político? - enfatiza a ação dos atores, a partir do foco na agência e nos agenciamentos recíprocos. Bebendo na fonte das abordagens pragmatista e relacional, partimos de dois pressupostos inter-relacionados: a agência 
possui natureza criativa, situada e relacional; a agência criativa, situada e relacional dos atores (re)produz estruturas relacionais que, ao mesmo tempo, agem sobre os atores. Baseando-nos nesses pressupostos, que detalharemos a seguir, sustentamos uma concepção agêntica do contexto para pensar a relação entre movimentos sociais e políticas públicas.

Nossa compreensão de agência enfatiza a criatividade dos atores e a inserção deles em relações de poder. Partimos aqui de um conceito genérico de agência, seguindo Giddens (1989, p. 7), para quem

"Agência" diz respeito a eventos dos quais um indivíduo é o perpetrador, no sentido de que ele poderia, em qualquer fase de uma dada sequência de conduta, ter atuado de modo diferente. O que quer que tenha acontecido não o teria se esse indivíduo não tivesse interferido.

Assim, agência tem a ver com a capacidade ou o poder de produzir efeitos na realidade. Associar agência com poder não significa entender o agente como livre dos efeitos do poder dos outros. Agência não deve ser confundida com uma condição "heroica" em que o ator ganha forças extraordinárias que o livram das amarras sociais (Clegg, 2010). Para Giddens (1989), agência e estrutura são intimamente interligadas, e as estruturas somente se reproduzem através da ação. No entanto, embora o autor veja o agente como knowledgable e, portanto, capaz de compreender e criticar as estruturas sociais, seu modelo enfatiza a reprodução de estruturas em detrimento de teorizar sobre como pode ocorrer uma agência transformadora (Sewell, 1992).

Autores influenciados pelo pragmatismo vêm avançando na explicação da mudança ao buscarem uma concepção mais dinâmica da agência, que compreende os atores como situados em relações sociais existentes e, ao mesmo tempo, capazes de agir criativamente a partir dos recursos 
que aquelas relações propiciam. Na sua obra clássica sobre a sociologia da ação, Joas (1996) argumenta que a literatura nos impõe uma escolha insatisfatória entre duas concepções. Na primeira, o ator racional "calcula" custos e benefícios a partir dos incentivos apresentados pelo contexto. $\mathrm{Na}$ segunda, as normas culturais predeterminam a ação individual. Joas busca romper com essa distinção propondo que a ação é criativa, simultaneamente situada e reflexiva. A concepção pragmatista, da qual ele parte, entende o ator como localizado em um contexto "problemático", que dificulta respostas rotineiras, automatizadas, mas não implica que o ator pode fazer qualquer coisa. Para lidar com problemas, atores somente podem usar os recursos encontrados no contexto em que se situam. Ao mesmo tempo que limita o que atores podem fazer, essa distribuição de recursos serve como matéria-prima da própria ação (Bevir e Rhodes, 2010; Joas, 1996).

A abordagem criativa precisa ser combinada, no entanto, com uma concepção relacional da ação: ou seja, agência é sempre interação e relação, não ação isolada ${ }^{4}$. Para que a abordagem relacional seja coerente com a perspectiva da agência criativa, é necessário entender que os vínculos entre os atores não são estruturas inertes, deterministas, mas formam redes sociais que são ao mesmo tempo pré-construídas e transformáveis. Assim, nosso debate sobre agência tem sintonia com a perspectiva construtivista de redes sociais, conforme Emirbayer e Goodwin (1994, p. 1445), para quem estas simultaneamente limitam e possibilitam a ação humana.

Dizer que redes sociais são estruturas preexistentes, constantemente reconstruídas pelas interações humanas, não quer dizer que todos os atores na interação são dotados

\footnotetext{
4 Abers e Keck (2017) buscam combinar a perspectiva pragmatista com a relacional ao argumentarem que a ação transformadora tende a ter uma dimensão "experimental" e outra "relacional".
} 
dos mesmos recursos e da mesma capacidade de agir. Pelo contrário, abordagens relacionais enfatizam que a agência de qualquer ator é afetada por sua localização nas estruturas relacionais em que se insere. $\mathrm{Na}$ análise de redes sociais, por exemplo, atores com mais centralidade ou que operam como pontes têm acesso diferenciado aos recursos da rede e logo ocupam posições de superioridade nela em determinado momento (Diani, 2003, p. 107). Na teoria dos campos de Pierre Bourdieu (1989), por sua vez, a posição dos atores na estrutura relacional do campo é definida pela distribuição desigual dos recursos que conferem poder (capitais). Seja em função de desigualdades na forma e no tipo de vínculos dos atores, seja em função de desigualdades no acesso e uso de recursos que conferem poder, atores tendem a interagir em condições desiguais e, assim, apresentam capacidades de agência desiguais.

Essa concepção de agência criativa, situada e relacional tem implicações diretas na forma de abordar as relações entre os atores e destes com seu contexto de ação. Isso nos leva à segunda ideia que embasa nosso argumento: $a$ agência criativa, situada e relacional dos atores (re)produz estruturas relacionais que, ao mesmo tempo, agem sobre os atores. A ação conjunta e interdependente de diversos atores, em geral em condições de desigualdade, produz estruturas relacionais.

Essa formulação se baseia em grande medida no trabalho de Jasper (2012), que propõe uma concepção tanto de movimentos quanto das instituições políticas como configurações de atores dotadas de agência. Para Jasper, "contextos" deveriam ser entendidos como configurações de atores agindo de forma recíproca e interdependente. Por exemplo, governos são compostos de atores, que reagem não somente a outros atores políticos, mas aos próprios movimentos. Da mesma maneira que os movimentos mobilizam protestos quando identificam oportunidades políticas, o autor salienta que as elites políticas podem entender protestos como 
oportunidades para propulsionar mudanças que desejam. Ou seja, a mútua constituição não ocorre entre algo sólido e inanimado e um ator coletivo, e sim entre atores com acesso diferenciado a recursos institucionais. O "ambiente" em que movimentos atuam não é externo a eles e sim um conjunto de outros atores com os quais aqueles interagem ${ }^{5}$.

É também fundamental compreender que uma concepção de "contextos" como estruturas relacionais não implica na ideia de que essas sejam compostas somente por atores interagindo "no presente". Ao contrário, como enfatiza a ideia de agência situada, os atores sempre agem a partir de condições produzidas e instituídas por ações passadas. Tal perspectiva atende ao alerta de Thompson (1993, p. 67):

olhemos a história como história - homens e mulheres situados em contextos reais (que eles não escolheram) e confrontados perante forças incontornáveis com uma urgência esmagadora de relações e deveres, dispondo, apenas, de uma oportunidade restrita para inserir sua própria agência.

Uma estrutura relacional é, assim, um produto histórico, em que certas práticas e ideias se cristalizam em normas e papéis sociais e em que recursos são distribuídos de maneira desigual. Essas cristalizações, comumente chamadas de instituições, também possuem agência sobre os atores.

Partindo dessa concepção agêntica de atores e instituições, nosso argumento central é que movimentos que

\footnotetext{
${ }_{5}^{5}$ Para operacionalizar essa perspectiva, Jasper (2004, 2012) propõe substituir a antinomia "estrutura e agência", conceitos que ele considera demasiadamente abstratos, por "jogadores" engajados em "interações estratégicas". Embora a concepção de agência de Jasper não seja exatamente racionalista (ele é um dos principais defensores da ideia de que emoções importam para a análise dos movimentos sociais), sua redução de agência a uma noção de ação estratégica parece dar pouca atenção à complexidade do processo decisório de um ator situado, algo que consideramos melhor resolvido com a proposta pragmatista e relacional apresentada.
} 
constroem e disputam políticas agem criativamente, interagindo ativamente com os agenciamentos de outros atores e instituições com os quais apresentam relações de interdependência. São essas interações (presentes e passadas) que conformam aquilo que a literatura tradicionalmente tem denominado de contexto político.

Assim, problematizar a externalidade e, em alguns casos, a própria separação entre os movimentos e os atores políticos e instituições não pode implicar em desconsiderar as assimetrias de poder resultantes do acesso desigual aos recursos estatais disponíveis a diferentes tipos de atores, nem em ignorar as relações de poder que influenciam a maneira como tais recursos podem ser usados. Dizer que atores de movimentos sociais interagem com outros atores em estruturas relacionais - como subsistemas de políticas públicas ou regimes - não significa que aquela interação acontece em condições igualitárias. Mas estar em desvanta30 gem ou ser marginalizado em uma relação é diferente de estar excluído dela.

\section{Estruturas relacionais: regime e subsistemas}

Em Tatagiba, Abers e Silva (2018), defendemos que os movimentos sociais são um tipo particular de ator/rede que participa do processo de produção de políticas públicas, elaborando, experimentando e disputando modelos alternativos de políticas. A produção das ideias e o desenvolvimento das experiências, que subjazem à formulação dos modelos alternativos, sempre ocorrem em interação com outros atores (aliados, concorrentes, adversários), e seus resultados dependem de como essas interações se estruturam e desenvolvem. Afirmamos também que as oportunidades de influência dos movimentos nos processos de formulação e implementação das políticas públicas são duplamente condicionadas - pelo regime e pelos subsistemas de política pública. Articulando esses argumentos iniciais com os 
pressupostos teóricos expostos na seção anterior, buscamos agora compreender como os conceitos de regime e subsistemas podem ser mobilizados para uma interpretação agêntica e relacional do contexto político.

\section{Regime}

O conceito de regime tem uma longa tradição na ciência política, remetendo, grosso modo, ao conjunto das instituições e ideias que regulam a luta pelo poder e seu exercício em uma sociedade. Na área de estudos do confronto político, o termo recebe uma conotação particular, desenvolvida por Tilly (2006, 2008), que busca compreender como regimes políticos afetam os repertórios de confronto e vice-versa.

As formulações de Tilly apresentam algumas ambiguidades no tratamento das relações entre regime e movimentos sociais. Por um lado, o autor expressa uma definição relacional de regime que inclui atores estatais e não estatais. Nas palavras dele:

Quando as interações entre um par de atores se repetem de forma similar, nós começamos a falar de uma relação entre atores. Nós, então, descrevemos um regime em termos das relações prevalecentes entre os atores políticos, incluindo o governo (Tilly, 2006, p. 19).

Essa concepção se adequa a nossa proposta de definir regime político como uma estrutura relacional constituída pelos atores estatais e não estatais que têm acesso às discussões e decisões governamentais. Por outro lado, Tilly (2006) tende a tratar regimes como algo externo que condicionaria as formas assumidas pelo confronto político em cada contexto. Grande parte da sua discussão sobre regimes foca a formulação de uma tipologia de regimes a partir de características estruturais, como níveis de capacidade estatal e de democracia. Dessa tipologia se desdobra o argumento de 
que diferentes tipos de regime ofereceriam mais ou menos oportunidades à ocorrência de distintas formas de contestação política, entre as quais os movimentos sociais. O modo como Tilly constrói este argumento tende a presumir que os atores contestatórios são necessariamente distintos dos atores que conformam os regimes (Jasper, 2012).

A falta de uma discussão mais agêntica dos regimes em Tilly é estranha, dado que, como Gross (2010) mostra na discussão de repertórios, o autor utiliza uma concepção de ação humana que se aproxima fortemente da vertente pragmatista e relacional que propomos. Repertórios para Tilly (2006, p. 35) são conjuntos de rotinas de reivindicação que têm “caráter agrupado, aprendido, porém improvisado". Ou seja, são formas de agir, ao mesmo tempo definidas historicamente e constantemente transformadas pela criatividade dos atores em situações específicas. $\mathrm{O}$ autor, no entanto, não usa a mesma concepção agêntica para discutir regimes. Apesar de defini-los como padrões de interação, na operacionalização empírica Tilly normalmente os trata como contextos com características que afetam e são afetadas pela ação contestatória, e não como arenas onde a ação ocorre.

Outros autores apresentam definições de regime que incluem os movimentos mais claramente. Para Baiocchi (2005, p. 18), "Regimes Estado-Sociedade Civil são os padrões estáveis de interações entre Estado e Sociedade Civil, cuja característica definidora é a forma como as demandas societais são reconhecidas". Assim, diferentes regimes EstadoSociedade Civil, ao apresentarem e possibilitarem distintas formas de reconhecimento das demandas societárias, tenderiam a oferecer maiores ou menores oportunidades para a atuação de atores como os movimentos sociais, envolvidos centralmente na construção e expressão de tais demandas.

Outra formulação de regimes que apresenta similaridades com a nossa é elaborada por Dufour e Ancelovici (2018, p. 165), que definem um "regime de cidadania" como "a 
forma que um Estado particular enquadra (legalmente e através de ação pública) as relações que estabelece com seus cidadãos". Um aspecto importante desse conceito é a ênfase conferida às "heranças" de processos passados na conformação institucional do regime.

Embora a referência a regimes remeta ao conjunto dos atores políticos relevantes numa dada sociedade, vale a pena esclarecer que em cada momento existe uma coalizão governante que centraliza decisões do governo federal. Para Stone (1989, p. 5), a ideia de coalizão governante "nos obriga a enfrentar o fato de que arranjos informais são amarrados por um grupo central - tipicamente um grupo de insiders - que se encontram regularmente na tomada de decisões". Nesse sentido, em diferentes coalizões políticas variam as formas de interação, as demandas societárias reconhecidas e os atores e interesses que têm acesso e influência nos processos decisórios governamentais.

Em síntese, regimes são compostos pela estrutura das relações entre atores politicamente relevantes da sociedade e do Estado e destes com arranjos institucionais, regras e ideias instituídos pelos conflitos políticos e por políticas públicas do passado, e são liderados por coalizões governantes. A posição ocupada pelos atores e interesses dos movimentos sociais no regime define oportunidades e/ou obstáculos para reconhecimento, acesso e influência institucional de tais atores e interesses. Em diferentes regimes, movimentos sociais terão distintas possibilidades de avançar em suas causas, em função do lugar que ocupam no regime e na relação na/com a coalizão governante.

\section{Subsistemas}

Existe uma longa tradição no campo de políticas públicas de explicar a variação setorial com base nas diferentes configurações relacionais entre atores especializados em um tema, como saúde, segurança, moradia, etc. Redes de política 
pública, redes temáticas, comunidades de política pública, comunidades epistêmicas e subsistemas de política pública são alguns dos conceitos usados para descrever e analisar esses campos temáticos de interação. Aqui abordamos essas estruturas relacionais setoriais a partir do conceito de subsistema.

Desde os anos de 1950, os subsistemas são definidos na ciência política como campos "compostos de um número limitado de atores e instituições, geralmente reunidos em grupos mais ou menos coesos, que se especializam e direcionam seus esforços para algumas questões específicas em relação a uma política" (Capella e Brasil, 2015, p. 58). Subsistemas têm uma dinâmica que parcialmente independe do regime vigente: as comunidades de políticas que integram os subsistemas debatem propostas e buscam colocar ideias na agenda, muitas vezes a despeito dos interesses expressos pelas coalizões de governo (Capella e Brasil, 2015, p. 65).

Como os outros conceitos mencionados, o de "subsis34 tema” chama a atenção para o fato de políticas públicas serem produzidas através das interações entre múltiplos tipos de atores estatais e não estatais (Rhodes, 2006). Desde os anos 1970, autores como Heclo (1978 apud Capella e Brasil, 2015) criticam a tese do "triângulo de ferro", segundo a qual as políticas surgiriam da interação entre três tipos de elite: parlamentares, burocratas e grupos de interesse. Para Howlett e Ramesh (1998), o conceito de subsistemas possibilita identificar a existência não somente de atores estatais e grupos de interesse, mas também de grupos mobilizados por expertise ou comprometimento com um tema:

O principal impulso da literatura de subsistemas de políticas é sua tentativa de derivar uma concepção dos principais atores das políticas que transcende as distinções tradicionais "positivistas" entre agentes e estruturas, e especialmente entre atores estatais e sociais, definidos institucionalmente (Howlett e Ramesh, 1998, p. 469-469). 
Embora o termo subsistema tenha sido utilizado por vários autores, os proponentes do Modelo de Coalizões de Defesa (Advocacy Coalition Framework) apresentam uma acepção especialmente interessante para nossos fins. Nas palavras de Jenkins-Smith; St. Clair e Woods (1991, p. 852):

Concebemos o processo de políticas públicas como operando dentro de "subsistemas de políticas públicas" parcialmente segmentados, compostos das instituições e atores que estão diretamente envolvidos no processo de políticas públicas em uma área especializada de política. Membros de subsistemas incluem representantes de empresas, grupos de interesses, associações comerciais, órgãos do executivo e comissões legislativas, bem como autoridades eleitas, estudiosos e jornalistas que regularmente acompanham e buscam influenciar o curso de uma política pública na área temática.

Essa perspectiva compreende cada subsistema como formado não por uma única "rede", mas por várias "coalizões de defesa". Assim, subsistemas aparecem como arenas de disputa. A dinâmica de subsistemas é caracterizada pelo conflito entre diferentes ideias, defendidas por diferentes coalizões, o que resulta em mudança ou "aprendizado". O processo de mudança ocorre ao mesmo tempo por dentro do subsistema e em função de mudanças externas na sociedade mais ampla (Sabatier e Jenkins-Smith, 1993).

Há, no entanto, duas limitações no conceito de subsistema apresentado por Jenkins-Smith e colegas. Primeiro, movimentos sociais estão notavelmente ausentes ${ }^{6}$. Segundo, o Modelo de Coalizão de Defesa tende a presumir que coalizões naturalmente interligam atores que compartilham

\footnotetext{
${ }^{6}$ A literatura de políticas públicas tende a tratar os atores societários de forma unificada, a partir do conceito de "grupos de interesse". Não há, no entanto, uma discussão específica e aprofundada sobre movimentos sociais.
} 
as mesmas crenças. Essa maneira de pensar a ligação entre ideias e relações sociais vai de encontro com a proposta que elaboramos em Tatagiba, Abers e Silva (2018), na qual defendemos uma visão relacional e experimental da construção de ideias de política pública. Ou seja, ideias não antecedem as interações entre os atores, mas são construídas e transformadas através delas.

Mesmo assim, a abordagem dos subsistemas propõe uma perspectiva fértil para explorar analiticamente a (maior ou menor) heterogeneidade do Estado contemporâneo e particularmente analisar distintas oportunidades e constrangimentos que essa heterogeneidade coloca para a inserção e atuação dos movimentos sociais em diferentes subsistemas. Compreender o "setor" de política como uma estrutura relacional nos permite explorar a ação de movimentos sociais que defendem modelos alternativos não apenas por meio de atos de protesto e contestação, mas também pela participação em disputas entre diferentes coalizões no interior do subsistema.

Assim, enquanto o regime nos permite tematizar as configurações relacionais de poder que importam para a ação dos movimentos sociais sobre as políticas públicas, o conceito de subsistema nos permite captar as variações no interior do regime em razão das configurações de poder específicas a cada setor de política pública, que conferem aos movimentos sociais diferentes condições de acesso e influência. Sob uma mesma coalizão de governo, subsistemas de políticas públicas podem variar significativamente na sua abertura à atuação de movimentos sociais.

A política ambiental, por exemplo, sempre foi marginalizada nos governos federais brasileiros (regimes). Mas, em função de certo apoio internacional, criou-se ao longo dos anos 1990 um conjunto de políticas (subsistema) a que as entidades ambientalistas tiveram amplo acesso (Abers et al., 2000). A mudança de regime representada pela eleição 
de Lula ampliou o acesso ao governo por parte de movimentos mais próximos à coalizão governante. A nomeação de Marina Silva - liderança do partido do presidente e que também tinha laços fortes com entidades ambientalistas - para o Ministério de Meio Ambiente possibilitou que diversos ambientalistas ocupassem cargos importantes (Losekann, 2009; Oliveira, 2016). De maneira similar, a nomeação de Olívio Dutra - outra pessoa com papel central no partido - como ministro das Cidades criou um canal de acesso para o Movimento de Reforma Urbana dentro do governo federal (Serafim, 2013). Em outras áreas, no entanto, movimentos sociais não se beneficiaram desse tipo de conexão. Assim, podemos entender que quando membros de movimentos sociais ocupam posições importantes dentro do regime, as possiblidades de acesso aumentam. Da mesma maneira, mudanças na coalizão - como a saída da Marina Silva e seu voo próprio como candidata, ou a decisão de substituir Olívio por Marcio Fontes, do Partido Progressista (PP), em função do mensalão - podem ter efeitos dramáticos na capacidade de movimentos sociais manterem influência sobre as políticas.

Quando tais mudanças ocorrem, a consolidação do subsistema de maneira relativamente independente do apoio político da coalizão pode ser chave. No caso ambiental e das Cidades, pesquisas mostram que a absorção de ideias de movimentos sociais no interior da burocracia ajudou a sustentar as políticas mesmo na ausência de apoio político em nível mais alto (Viana, 2017). O golpe de 2016 também teve efeitos distintos em subsistemas mais consolidados - como a saúde, cujo Conselho Nacional emergiu como uma importante fonte de resistência ao desmonte da política (Rezende, 2018) - e menos consolidados - como no caso da Economia Solidária, que dependia fortemente de alguns atores petistas para sua sobrevivência como política pública e foi em grande medida desmantelada a partir de 2016. 
Ao invés de apresentar constatações empíricas e/ou genéricas de que o "contexto importa", o modelo proposto espera apoiar a identificação de processos e mecanismos de interação entre diferentes estruturas relacionais e seus atores. Isso significa não apenas definir tipologias e categorias de análise (subsistemas mais e menos consolidados, regimes mais ou menos permeáveis aos movimentos), mas também explorar o modo como atores em diferentes tipos de subsistemas e regimes interagem e exercem suas agências.

\section{Considerações finais e agenda de pesquisa}

Este artigo buscou contribuir para o desenvolvimento da agenda de pesquisa acerca das relações entre movimentos sociais e políticas públicas, oferecendo um modelo para a análise do contexto político enquanto estrutura relacional de poder. Inspirados pela abordagem relacional e pragmática sugerimos que, ao invés de se relacionarem com um "contexto político" objetivado e externo, os movimentos sociais se inserem em relações de interdependência envolvendo diversos atores e instituições com os quais interagem rotineiramente. As oportunidades e os constrangimentos confrontados pelos movimentos sociais na atuação nas políticas públicas passam a se enquadrar como produtos de agenciamentos simultâneos e recíprocos de diversos atores, redes e instituições, incluindo os próprios movimentos.

Apresentamos duas configurações dessas estruturas que condicionam as formas de acesso, desenvolvimento e resultados da ação dos movimentos nas políticas públicas: os regimes e os subsistemas. Cada regime e subsistema de política pública tem uma configuração distinta, produzida pelas agências situadas, relacionais e, em geral, desiguais dos diversos atores que o integram. Nessa perspectiva, os movimentos sociais não se relacionam com o regime ou com os subsistemas - conforme se depreenderia de uma formulação 
contextualista da relação entre movimentos sociais e políticas públicas -, mas no regime e no subsistema.

Os conceitos de regime e subsistema possibilitam distinguir as estruturas relacionais nas quais os movimentos atuam que são importantes para a análise. Os atores do subsistema são as coalizões que se constroem em torno de determinadas ideias de política pública, enquanto o regime é composto por interações entre atores políticos relevantes que, conduzidos por coalizões de governo, afirmam e defendem projetos de sociedade. A capacidade de agir de forma repressiva ou de alocar recursos vultuosos somente possíveis através do financiamento público tende a ser uma exclusividade dos atores do regime. Já definir o que é competência técnica no âmbito de certa política e quem são os atores dotados de tal competência costuma ser uma ação dos atores do subsistema. Nesse sentido, o regime tende a estabelecer parâmetros mais gerais para a relação entre Estado e sociedade civil, a partir dos quais os movimentos sociais constroem seus repertórios. Mas pode haver variações significativas entre os subsistemas em termos das condições que estabelecem para os atores construírem seus repertórios. As especificidades das burocracias em cada subsistema - particularmente das relações destas com os movimentos sociais e suas causas - é um dos elementos para explicar tais variações.

Como o posicionamento em estruturas relacionais afeta o acesso a recursos, a possiblidade de disseminar ideias, as oportunidades de participar das deliberações? Como atores conseguem transformar suas posições nessas estruturas? Responder a esse tipo de pergunta exige uma especificação das formas como ocorrem os agenciamentos recíprocos entre atores e instituições atuantes nos regimes e subsistemas e, especialmente, como tais agenciamentos permitem explicar o que é produzido em termos de políticas públicas. Da mesma forma, será preciso identificar como as estruturas relacionais de regimes e subsistemas afetam o acesso de 
diferentes atores a recursos que possibilitam influenciar o desenho ou implementação de uma política pública específica. Através da comparação sistemática das configurações de regimes e subsistemas e das interdependências destes e seus atores, esperamos avançar mais na análise sobre como as ações de movimentos sociais para influenciar políticas ocorrem e o que elas produzem.

\section{Rebecca Neaera Abers}

possui graduação em Social Studies pela Harvard University (1988), mestrado e doutorado em Planejamento Urbano pela University of California Los Angeles (1992 e 1997). Atualmente é professora associada da Universidade de Brasília. Desenvolve pesquisas sobre as relações entre estado e sociedade civil, burocracia, criatividade política, ativismo e transformação institucional, gestão de água e comitês de bacia hidrográfica, políticas participativas, movimentos 40 sociais. É uma das coordenadoras do Grupo de Pesquisa Repensando as Relações Sociedade e Estado (Resocie).

\section{Marcelo Kunrath Silva}

doutor em Sociologia pela Universidade Federal do Rio Grande do Sul (2001), é professor titular do Departamento de Sociologia da Universidade Federal do Rio Grande do Sul. Desenvolve pesquisas na área de sociologia política e, desde 2009, coordena o Grupo de Pesquisa Associativismo, Contestação e Engajamento (GPACE).

\section{Luciana Tatagiba}

é professora livre-docente do Departamento de Ciência Política da Unicamp. Realizou seu mestrado no Programa de Pós-Graduação em Ciência Política, e o doutorado no Programa de Pós-Graduação em Ciências Sociais, ambos na Universidade Estadual de Campinas (Unicamp). Desde 2008 é uma das coordenadoras do Núcleo de Pesquisa em 
Participação, Movimentos Sociais e Ação Coletiva (NepacUnicamp). Desenvolve pesquisas sobre democracia e participação, movimentos sociais e protestos no Brasil.

\section{Bibliografia}

ABERS, Rebecca Neaera. 2018. Bureaucratic activism: pursuing environmentalism inside the Brazilian State. Latin American Politics and Society, New Jersey. No prelo.

ABERS, Rebecca Neaera; VON BÜLLOW, Marisa; LITTLE, Paul; MILLIKAN, Brent. 2000. Civil society participation in the Pilot Program to Conserve the Brazilian Rain Forest. Washington D.C., World Bank Strategic Compact /Rain Forest Trust Fund. Estudo não publicado.

ABERS, Rebecca Neaera; KECK, Margaret E. 2017. Autoridade prática: ação criativa e mudança institucional na política das águas do Brasil. Rio de Janeiro: Editora Fiocruz.

ABERS, Rebecca Neaera; SERAFIM, Lizandra; TATAGIBA, Luciana. 2014. Repertórios de interação Estado-sociedade em um Estado heterogêneo: a experiência na era Lula. Dados, Rio de Janeiro, v. 57, n. 2, pp. 325-357.

AMENTA, Edwin; HALFMANN, Drew. 2012. Opportunity knocks: the trouble with political opportunity and what you can do about it. In: GOODWIN, Jeff; JASPER, James (orgs.). Contention in context: political opportunities and the emergence of protest. Stanford: Stanford University Press. pp. 227-239.

ASSIS, Thiago Rodrigo de Paula. 2009. Sociedade civil, Estado e políticas públicas: reflexões a partir do Programa Um Milhão de Cisternas Rurais (P1MC) no estado de Minas Gerais. $158 \mathrm{f}$. Tese de Doutorado em Ciências Sociais. Rio de Janeiro: Seropédica.

AVRITZER, Leonardo; NAVARRO, Zander. 2003. A inovação democrática no Brasil: o orçamento participativo. São Paulo: Cortez.

BAIOCCHI, Gianpaolo. 2005. Militants and Citizens: the politics of participatory democracy in Porto Alegre. Stanford: Stanford University Press.

BEVIR, Mark; RHODES, Roderick Arthur William. 2010. The State as cultural practice. Oxford: Oxford University Press.

BLANCO, Ismael; LOWNDES, Vivien; PRATCHETT, Lawrence. 2009. Re-organising Babylon: on the meaning of policy networks and network governance and their democratic consequences. Paper prepared for 
the conference Governance Networks: Democracy, Policy Innovation and Global Regulation, Roskilde University.

BLIKSTAD, Karin. 2017. Movimentos sociais de pessoas pobres: entre as urgências e o direito. 266 f. Tese de Doutorado em Ciência Política. Campinas: Unicamp.

BOURDIEU, P. 1989. O poder simbólico. Lisboa: Difel.

BRANDÃO, Igor Ribas. 2018. Governar o desperdício: a inclusão de catadores no regime brasileiro de políticas de resíduos. $260 \mathrm{f}$. Tese de Doutorado em Ciência Política. Brasília, DF: UnB.

CAPELLA, Ana Cláudia Niedhardt; BRASIL, Felipe Gonçalves. 2015. Análise de políticas públicas: uma revisão da literatura sobre o papel dos subsistemas, comunidades e redes. Novos estudos Cebrap, São Paulo, n. 101, pp. 57-76.

CLEGG, Stewart. 2010. The State, power, and agency: missing in action in institutional theory? Journal of Management Inquiry, London, v. 19, n. 1, pp. 4-13.

CONTI, Irio Luiz. 2016. Organizações sociais e políticas públicas: inserção da Fetraf-Sul nas políticas públicas de segurança alimentar e nutricional. 329 f. Tese de Doutorado em Desenvolvimento Rural. Porto Alegre: UFRGS.

42 CORTES, Soraya Vargas (org.). 2009. Participação e saúde no Brasil. Rio de Janeiro: Editora Fiocruz. 2015. Policy community defensora de direitos e a transformação do Conselho Nacional de Assistência Social. Sociologias, Porto Alegre, v. 17, n. 38, pp. 122-154.

DAGNINO, Evelina; OLVERA, Alberto J.; PANFICHI, Aldo. 2006. Para uma outra leitura da disputa pela construção democrática na América Latina. In: A disputa pela construção democrática na América Latina. São Paulo: Paz e Terra, 2006. pp. 13-92.

DIANI, Mario. 2003. "Leaders" or Brokers? Positions and Influence in Social Movement Networks. In: DIANI, Mario; McADAM, Doug. Social movements and networks: relational approaches to collective action. Oxford: Oxford University Press. pp. 104-122.

DOWBOR, Monika. 2012. Arte da institucionalização: estratégias de mobilização dos sanitaristas (1974-2006). 288 f. Tese de Doutorado em Ciência Política. São Paulo: USP.

DUFOUR, Pascale; ANCELOVICI, Marcos. 2018. From citizenship regimes to protest regimes? In: PAQUET, Mireille; NAGELS, Nora; FOUROT, Audet-Claire. Citizenship as a regime. Kingston: McGillQueen's University Press. pp. 165-185. 
EMIRBAYER, Mustafa. 1997. "Manifesto for a relational sociology". The American Journal of Sociology, Chicago, v. 103, n. 2, pp. 281-317.

EMIRBAYER, Mustafa; GOODWIN, Jeff. 1994. Network analysis, culture, and the problem of agency. The American Journal of Sociology, Chicago, v. 99, n. 6, pp. 1411-1454.

GAMSON, William. 1975. The strategy of social protest. Homewood: The Dorsey Press.

GIDDENS, Anthony. 1989. A constituição da sociedade. São Paulo: Martins Fontes.

GOLDSTONE, Jack. A. 2004. More social movements or fewer? Beyond political opportunity structures to relational fields. Theory and Society, New York, v. 33, pp. 333-365.

GOODWIN, Jeff; JASPER, James. 1999. Caught in a winding, snarling vine: the structural bias of political process theory. Sociological Forum, New York, v. 14, n. 1, pp. 27-54.

GRISA, Catia. 2012. Políticas públicas para a agricultura familiar no Brasil: produção e institucionalização das ideias. 281 f. Tese de Doutorado em Ciências Sociais. Rio de Janeiro: UFRRJ.

GROSS, Neil. 2010. Charles Tilly and American pragmatism. The American Sociologist, New York, v. 41, n. 4, pp. 337-357.

GUTIERRES, Kellen Alves. 2015. Projetos políticos, trajetórias e estratégias: a política de assistência social entre o partido e o Estado. $253 \mathrm{f}$. Tese de Doutorado em Ciências Sociais. Campinas: Unicamp.

HOCHSTETLER, Kathryn; KECK, Margaret E. 2007. Greening Brazil: environmental activism in state and society. Durham; London: Duke University Press.

HOWLETT, Michael; RAMESH, M. 1998. Policy subsystem configurations and policy change: operationalizing the postpositivist analysis of the politics of the policy process. Policy Studies Journal, New Jersey, v. 26, n. 3, pp. 466-481.

JASPER, James. 2004. A strategic approach to collective action: looking for agency in social-movement choices. Mobilization, Chicago, v. 9, n. 1, pp. 1-16.

2012. Introduction: from political opportunity structures to strategic interaction. In: GOODWIN, Jeff; JASPER, James (orgs.). Contention in context: political opportunities and the emergence of protest. Stanford: Stanford University Press, pp. 1-36.

JENKINS-SMITH, Hank C.; ST. CLAIR, Gilbert K.; WOODS, Brian. 1991. Explaining change in policy subsystems: analysis of coalition 
stability and defection over time. American Journal of Political Science, Washington, DC, v. 35, n. 4, pp. 851-880.

JOAS, Has. 1996. The creativity of action. Chicago: University of Chicago Press.

LAVALLE, Adrian Gurza et al. (orgs). 2018. Movimentos sociais e institucionalização: políticas sociais, raça e gênero no Brasil póstransição. Rio de Janeiro: Editora UERJ. No prelo.

LEITÃO, Leonardo Rafael Santos; SILVA, Marcelo Kunrath. 2017. Institucionalização e contestação: as lutas do Movimento Negro no Brasil (1970-1990). Política e Sociedade, Florianópolis, v. 16, pp. 315-347.

LOSEKANN, Cristiana. 2009. A presença das organizações ambientalistas da sociedade civil no governo Lula (2003-2007) e as tensões com os setores econômicos. 209 f. Tese de Doutorado em Ciência Política. Porto Alegre: UFRS.

LUCHMANN, Lígia Helena Hahn. 2002. Possibilidades e limites da democracia deliberativa: a experiência do orçamento participativo de Porto Alegre. 225 f. Tese de Doutorado em Ciência Política. Campinas: Unicamp.

MALVEZZI, Roberto. 2007. Semi-Árido: uma visão holística. Brasília, DF: Confea.

44 McADAM, Doug. 1982. Political process and the development of black insurgency, 1930-1970. Chicago: University of Chicago Press. . 1997. The political process model. In: BUECHLER, Steven; CYLKE Jr., Kurt (eds.). Social movements: perspectives and issues. Mountain View: Mayfield. pp. 172-192.

McADAM, Doug; TARROW, Sidney; TILLY, Charles. 2001. Dynamics of contention. Cambridge: Cambridge University Press.

OLIVEIRA, Marília Silva de. 2016. Movimento para as instituições: ambientalistas, partidos políticos e a liderança de Marina Silva. $306 \mathrm{f}$. Tese de Doutorado em Ciência Política. Brasília, DF: UnB.

PAVEZ, Thais Regina; TOLEDO, Demétrio Gaspari Cirne de; GONÇALVES, Renata da Rocha. 2009. Redes sociais, mobilização e segurança pública: evolução da rede de atores da segurança pública no processo preparatório da $1^{\text {a }}$ Conferência Nacional de Segurança Pública. Brasília, DF: Ministério da Justiça.

PIRES, Roberto Rocha Coelho; GOMIDE, Alexandre de Ávila. 2016. Governança e capacidades estatais: uma análise comparativa de programas federais. Sociologia e Política, Curitiba, v. 24, n. 58, pp. 121-143. 
REZENDE, Debora Almeida 2018. Where does participation go? Resistances and changes in repertoires of interaction inside and beyond the National Councils. Paper apresentado no XXXVI Congresso Internacional da Associação de Estudos Latino-Americanos, Barcelona. RHODES, Roderick Arthur William. 2006. Policy Network Analysis. In: MORAN, Michael; REIN, Martin; GOODIN, Robert E. (orgs.). Oxford Handbook of Public Policy. Oxford, New York: Oxford University Press, pp. $425-447$.

ROMÃO, Wagner de Melo. 2010. Nas franjas da sociedade política: estudo sobre o orçamento participativo. $235 \mathrm{f}$. Tese de Doutorado em Ciência Política. São Paulo: USP.

RUBIM, Antonio Albino Canelas; FERNANDES, Taiane; RUBIM, Iuri (orgs.). 2010. Politicas culturais, democracia e conselhos de cultura. Salvador: Edufba.

SABATIER, Paul; JENKINS-SMITH, Hank C. 1993. Policy change and learning: an advocacy coalition approach. Boulder: Westview Press. SANTANA, Vitor Leal; ARSKY, Igor da Costa. 2016. Aprendizado e inovação no desenho de regras para a implementação de políticas públicas: a experiência do Programa Cisternas. Revista do Serviço Público, Brasília, DF, v. 67, n. 2, pp. 203-226.

SERAFIM, Lizandra. 2013. Participação no governo Lula: as pautas da reforma urbana no Ministério das Cidades (2003-2010). Tese de Doutorado em Ciências Sociais. Campinas: Unicamp.

SEWELL, William H. 1992. A theory of structure: duality, agency, and transformation. American Journal of Sociology, Chicago, v. 98. n. 1, pp. $1-29$.

SILVA, Marcelo Kunrath. 2001. Construção da "participação popular": análise comparativa de processos de participação social na discussão pública do orçamento em municípios da Região Metropolitana de Porto Alegre/RS. 295 f. Tese de Doutorado em Sociologia. Porto Alegre: UFRS.

SILVA, Marcelo Kunrath; ROCHA, Ana Georgina; ALVES, Marcia Cristina. 2012. Desenvolvimento territorial e associativismo: uma análise comparativa. Tomo, São Cristóvão, v. 1, pp. 60-86.

SOUZA, Clóvis Henrique Leite de. 2016. Capacidades estatais para a promoção de processos participativos: uma análise das formas de organização das conferências nacionais. Tese de Doutorado em Ciência Política. Brasília, DF: UnB.

STONE, Clarence N. 1989. Regime politics: governing Atlanta - 1946-1988.

Lawrence: University Press of Kansas. 
TARROW, Sidney. 1994. Power in movement: Social movements, collective action and politics. Cambridge: Cambridge University Press.

TATAGIBA, Luciana; ABERS, Rebecca; SILVA, Marcelo Kunrath. 2018.

Movimentos sociais e políticas públicas: ideias e experiências na construção de modelos alternativos. In: PIRES, Roberto; LOTTA, G.; OLIVEIRA, V. E. de (orgs). Burocracia e políticas públicas no Brasil: interseções analíticas. Brasília, DF: Ipea/Enap. pp. 106-138.

TATAGIBA, Luciana; TEIXEIRA, Ana Claudia Chaves. 2018. "Movimentos sociais e a implementação de políticas públicas: a controversa novidade dos "programas associativos". In: TATAGIBA, Luciana; TEIXEIRA, Ana Cláudia Chaves (eds). Movimentos sociais e políticas públicas. Araraquara: Editora Unesp. no prelo.

2016. Efeitos combinados dos movimentos de moradia sobre os programas habitacionais autogestionários. Sociologia e Política, Curitiba, v. 24, n. 58, pp. 85-102.

TEIXEIRA, Ana Claudia Chaves. et al. 2016. A participação da sociedade na implementação de políticas públicas: a novidade dos "programas associativos". Trabalho apresentado no XL Encontro Anual da Anpocs, Caxambu.

THOMPSON, E. P. 1993. As peculiaridades dos ingleses. Textos Didáticos, Campinas, n. 10, pp. 9-98.

TILLY, Charles. 1978. From mobilization to revolution. An Arbor:

Addison-Wesley. 2006. Regimes and repertoires. Chicago: University of Chicago Press. 2008. Contentious performances. Cambridge: Cambridge University Press.

VIANA, Rafael Rocha. 2017. Programa Minha Casa Minha Vida Entidades: um olhar para a ação dos atores em torno das controvérsias. 147 f. Dissertação de Mestrado em Ciência Política. Brasília, DF: UnB. 


\section{MOVIMENTOS SOCIAIS E POLÍTICAS PÚBLICAS: REPENSANDO ATORES E OPORTUNIDADES POLÍTICAS}

\section{REBECCA NEAERA ABERS \\ MARCELO KUNRATH SILVA \\ LUCIANA TATAGIBA}

Resumo: O estudo da participação de movimentos sociais na produção das políticas públicas é uma agenda em franco desenvolvimento no Brasil e na literatura internacional. Neste artigo buscamos colaborar com o desenvolvimento dessa agenda, ao oferecer um modelo analítico para abordar aquilo que a literatura tradicionalmente apreende como "contexto político", que condicionaria a atuação dos movimentos sociais nas suas tentativas de influenciar o Estado. Partindo de um diálogo crítico com a produção nacional e estrangeira, argumentamos que, em vez de se relacionarem com um contexto objetivado e externo que condiciona sua formação e ação, os movimentos sociais devem ser compreendidos como participantes em relações de interdependência com diversos atores e instituições com quem interagem rotineiramente, constituindo o que denominamos de estruturas relacionais. Na análise das relações entre movimentos sociais e políticas públicas, as estruturas relacionais especialmente relevantes analiticamente são os regimes políticos e os subsistemas de política pública. Nosso argumento é que os movimentos sociais não se relacionam com essas estruturas - conforme se depreenderia de uma formulação contextualista -, mas no interior delas, embora normalmente a partir de uma posição de desvantagem ou marginalização.

Palavras-chave: Movimentos Sociais; Políticas Públicas; Regime; Subsistema; Oportunidades Políticas; Agência. 


\section{SOCIAL MOVEMENTS AND PUBLIC POLICY: RETHINKING ACTORS AND POLITICAL OPPORTUNITIES}

Abstract: The study of how social movements participate in the production of public policies became a major research agenda in Brazil and around the world. In this article, we seek to collaborate with the development of this agenda by proposing an analytical model to approach what is traditionally thought of as the "political context," which would condition the actions of social movements in their attempt to influence the State. Through a critical dialogue with the national and international literatures, we argue that, instead of interacting with an objective, external context that conditions movement emergence and actions, social movements should be understood as participating in interdependence relationships with the variety of actors and institutions with whom they regularly interact, through what we call relational structures. In analyzing the relations between social movements and public policies, we highlight two relational structures: political regimes and policy subsystems. Our argument is that social movements do not interact with these relational structures, as a contextualist approach would presume, but rather within them, although normally from disadvantaged or marginalized positions.

Keywords: Social Movements; Public Policy, Regime, Subsystem, Political Opportunities, Agency.

Recebido: 17/07/18

Aprovado: 17/10/18 